Jere. He founds this opinion on experiments which he performed by giving small quantities of the cholers evacuations to white mice." (On Cholera, p. 112.) From some experiments detailed at length by Mr. John Marshall, of Irondon, in the British and Foreign Medico-Chirurgical Reviewo for April 1853, we may, I think, conclude that choleraic disease, yet unaccompanied with the algide symptoms of Asiatic cholera, may be communicated to animals, by the ingestion of the cholera stools of man. In a paper by Dr. Lauder Lindsay (Edinb. Med. and Surg. Journal, lxxxi, 1854, page 275), it appears the specific disease cholera was not generated by feeding dogs on choleraic vomit and eracuations, nor even on the blood drawn during life or taken from cholera cases after death. The effect was the production of a non-specific diarrhoea. Their general health did not appear to deteriorate or to act otherwise than as a predisposing cause to their suffering from cholera, after exposure to its exhalations. The diarrhœa generated appeared to be very violent, with griping, vomiting and cramps, and great exhaustion, but the expelled matters were always feculent. In two dogs the disease proved fatal. The rêsume from the experiments detailed, both by Dr. Lindsay and Mr. Marshall, thus appears to be that in all these cases diarrhœa more or less severe, and romiting were produced. This was the general rule. In some cases the symptoms were so severe that death resulted, but facal matter was continued to the last. The post mortem examinations of these cases wcre, howerer, defective. Moreover, in the few instances recorded where actual cholera is said to have been produced and to have been in the end fatal, I do not find it stated whether the urine was suppressed or not ; such circumstance, had it been present, would have gone far in my mind to prove that this diarrhoea was, after all, cholcra, modified in different animals. The experiments, so far as they go, are then inconclusive; besides, they certainly present no relation which is constant, to the quantity of focal matters swallowed; although, as a rule, a large quantity is more certain in its products.

I am not aware of any experiments that tend directly to prove that the evacuations of typhus and other malignant fevers have ever been expcrimented with in the same way. We may, however, reason by analogy that in some cases yellow ferer is propagated by the cvacuations. The black stools passed in many instances of this disease differ in nothing from black vomit; and black romit has been known, even when rubbed externally orer the body, to generate the disease.

The evidence from retention of diseased fæces is, however, more conclusive. I have already alluded to those bad cases of typhus and yellow ferer which are preceded by obstinate constipation. Among ourselves, the most familiar example of disease which, per se, proves the poisonous influence of diseased or putrid fæces, is afforded in that variety of puerperal mania which is so often induced by accumulations in the intestines. It should be remembered that the female after parturition is placed in those conditions most firvourable to absorption, as there has been loss of blood to a greater or lesser cxtent, and invariably as a concomitant more or less nervous shock. Absorption of any offensive matters under these circumstances is greatly facilitated. Now these cases are generally accompanied by more or less head symptoms-the head may or may not be warmer, but a slight incoherent delirium at first, often passing into mania, presents itself. The face is sallow, and the conjunctiva is tinged with bile ; the tongue is remarkably foul, the breath offensire, often frecal. The abdomen is very tumid and swollen, and in one or other of the iliac fossæ there is uneasiness, not to say tenderness, and on deep pressure frequently a large mass of faces may be detected. The motions arc peculiarly offensive, and in most cases emit that cadaveric odour which to $\mathrm{my}$ mind is so indicative of putrefaction in facal matters. The pulse is frequent, easily excited, from 100 to 120 , and a shivering fit often occurs, thus denoting that the entire system is impregnated with the poison. The locale of the disease is often strongly manifested in the progress of the case. Rapid purga- tion may come on; the head symptoms will be ameliorated, if not actually remored; but the pulse will fall in frequency and increase in strength as the offensire matters are removed, an effect which, being generally the reverse of that observed after violent purgation, I look upon as almost diagnostic of this form of frcal impregnation. - It is clear in such cases that something more than frocal accumulation is present here. The symptoms are those of a narcotic poison in its first effect with ferer, and cannot but be partially explained if looked upon as due only to mechanical irritation. There are besides similar examples of disease occurring in non-puerperal cases, as in many instances of mania.

I have mentioned an extreme case, but the variety of minor affections of the same kind, differing only in degree, is legion. In these cases the poison is in the prima vice primarily; and so long as it remains, so long will the disease be kept up.

\section{ON THE CHARACTER AND MODE OF INFIICTION OF WOUNDS OF THE FEMALE PUDENDA, CONSIDERED IN REFERENCE TO CRIMINAL CHARGES.}

By Joun Barrett, Esq., F.R.C.S., Senior Surgeort to the Bath Western Dispensary.

[Rcad at the Meeting of the Bath and Bristol Branch, April 21th, 1856.] [Concluded from page 510.]

ThE last of the three cases is one which caused a deep sensation of horror at the time of its occurrence, from the supposed manner in which the death was effected-by a pointed stick thrust up the vagina. It is the case of Regina $v$. Joseph Clarke, for the murder of his wife, Maria Christiana Clarke, at Bath, in February 1851. It was tried at the Taunton Assizes before Chief Baron Pollock.

Clarke was a carpenter, working near Bristol, his wife and children living at Bath. He had the character of being an industrious, sober man; his master had so high an opinion of him that he went to the expense of defending him ; but his wife, who, before her marriage, had been in a somewhat superior position to him, and had married him against the wishes of her friends, was a woman of the most drunken, dirty habits; the consequence was, that his children were grossly neglected, and his room was kept in a state of discomfort and filth. He was in the habit of returning to Bath every Saturday, and providing her with sufficient means for her own and their children's support. These, however, she soon spent in liquor; and, of course, the children were constantly in a state of half-starvation and wretchedness. On the evening, however, of her death, he returned, out of his usual habit-for it was only Monday -as he stated himself from anxiety respecting his children, but as presumed, on the side of the prosecution, with the intention of murdering her by means of a stick, with which he came provided, and which he himself stated he had picked up on his way home. Her conduct had recently been very gross, and this was supposed to have been the immediate provocation to the act; it was also stated by one of the witnesses, though very properly not accepted as evidence, that the witness had heard the wife say shortly before that her husband had read from a newspaper an account of an atrocious act of this description, committed by a pensioner (unless my memory fails me, he had destroyed his wife by piercing the womb or the bowels, per vaginam, with a sharpened stick); it was also supposed that if murder was designed at all, such a kind of murder was not unlikely to have suggested itself to a thoughtful mind like his. I mention these circumstances, becanse, as I shall presently have to take exception to the medical evidence, it is but fair to state what I think at the time may have influenced the judgment of those who gave it, as it undoubtedly did that of a large portion of the public against the prisoner. Clarke reached home about half-past six in the evening, 
and found his wifedrunk, his children starring and neglected, his room filthy. Shortly after entering his room a sound was heard as of the cracking of a stick, and the wife was heard to say "Don't, Clarke". Before that a little rustling noise was heard on the floor. About five or ten minutes afterwards, all being silent in the meanwhile, something fell very heavily on the floor in his apartment. A heavy scuffling and several heavy falls were heard, and the wife cried out "murder" several times. The prisoner had been seen about this time to come out of his room and go partly down stairs, then returning. Also, about this period one of the neighbours interfered; the door seems to have been partly open, probably so left by him on his return; the deceased was then standing up, with her face to the door, her hair hanging over her shoulders, very pale, as if fainting or dying, and using her hands as if trying to grasp something for support. The husband caught her back suddenly, endearouring to close the door against witness, who left; but shortly afterwards passing the door again, she saw the deceased sitting near the window on the floor, and looking very pale, her husband supporting her. Soon afterwards, when witness entered, she was dead, the husband endeavouring to restore her to consciousness. He expressed great alarm and anxiety that a surgeon should be sent for. In the room was found a pool of blood, partly fluid, partly coagulatedarterial and venous; a stick broken into three portions, which matched; there was blood on the stick, which, it was allowed, might have been obtained from that on the floor, as the portions were lying there. One of the medical witnesses considered the stick to have the appearance of having been scraped towards the extremity. Careful search was made, but no weapon, indeed nothing besides the stick, was found, by which the fatal wound might have been inflicted. The stick was about three feet long, and of the thickness of the forefinger; there was human hair, not pudendal, twisted about it, and there was the same lying about the floor. There was a pan, which had evidently been used for the purposes of nature, broken into three parts; no blood on it, only one human hair, and human excrement on the floor. When charged by the policeman at the time with the death of his wife, the prisoner said, "I am the cause of it. I came home last Saturday night, and found her drunk. I came home unexpectedly, to see how she was now, and found her drunk again. I pushed her down there (pointing towards the foot of the bed, where there was a large pool of blood). I afterwards lifted her up, and seated her on the window bench. I then beat her with a stick ;" the stick which was found, and which he said he had picked up on his way from Bristol. It was stated in evidence that he was in the habit of beating his wife with a stick when he found her drunk. He said that the hair on the floor was there when he came home; some spots of blood were found on the prisoner's hands.

The first surgeon found that the woman had been dead, when he arrived, probably ten or fifteen minutes. Hair had been torn from the right side of the head. There was a recent, not severe contusion, over the left eyebrow. Arms very dirty and much abraded. The legs and thighs were covered, and the boots and stockings saturated with blood which had proceeded from a wound of the rulva, and the loss of which, there could be no doubt, had caused her death.

The medical evidence went to state that this wound was situated in the right labium minus, about two and a half inches within the vulva, about an inch and $a$ half in length, jagged at its entrance, and in depth extending down about two inches and a half. It admitted about two inches of the index finger, extending one inch further downwards, outwards, and backwards, one quarter of an inch outwards; it then glanced over a portion of the bone of the pelvis, being downwards in direction; then it passed backward. If it had continued in its direction, it would have come out by the side of the anus behind, would have met with a plexus of veins, and a quantity of small arteries, and have produced effusion of blood to the extent of two or three pints. It grazed over the bone, separating the bead of a muscle (from the bone?). This bone would not have been in the way if the stick had passed up to the bowels. The wound appeared to have been produced by a blunt-pointed instrument. One of the medical witnesses considered it might possibly have been produced accidentally by a stick fixed in a particular direction; but the other two considered this impossible. No artery was divided large enough to account for the hæmorrhage, the fatality of which was no doubt hastened by her having been in the standing position during it.

The defence was, that the act was committed in a house full of lodgers, and that the supposition of murder under such circumstances was absurd; that the prisoner's charater and couduct alike were opposed to such a charge; that the principal medical witness acknowledged that he had never seen such a case before, and consequently the medical evidence could not be considered conclusive that the wound was not inflicted accidentally by her sitting down on the pan, and its breaking under her. As no witnesses, except to character, were called for the prisoner, it was necessary for his counsel to obtain the materials for his defence from those called by the prosecution, and principally from the medical witnesses. It was this point of accidental woundiug by the broken pan which he endearoured to establish by his cross-examination of them; but, as far as their evidence went, he failed. He exhibited in court part of a broken pint cup, the bottom with an upright angular part. It was said that he picked it up on his way to the court, remarking to his colleague, "This is our defence"; and he put it, whether such a wound might not have been produced by such a potsherd; but he failed in obtaining this admission, or that it might have been inflicted by the broken portions of the pan found in the room. It was acknowledged by one medical witness, but not by the others, that a wound two and a half inches in depth might be produced by an instrument not so long, owing to the elasticity of the parts allowing them to give way an inch and a half or so; but then it was held, that if the potsherd, with a puncturing portion of this length, had caused the wound, it would have been stained with the blood rushing out immediately on the wounding instrument, which it was not; that any of the pieces of the pan would have produced a larger external wound; that there was no grit or dirt in the wound; that the fæces about the room were not roided in deliquio animi, as then they would have had blood about them, but at some other time, and such an idea was consistent with her dirty habits, and consequently their being about the room gave no proof of the pan having been broken at the time of their being voided in the manner supposed; that the whole length of the wound had the jagged appearance of torn muscle, euch as a stick might produce; that if the wound was produced by an accidental blow, such as a dig with a stick, for instance, the bone underneath would give direction to the wound; a fall could not have produced the wound; an accidental blow, a violent dig, could.

The judge, in summing up, remarked that it was a case which had produced in his mind more anxiety, he had almost said, than he had ever felt before, certainly more than he had on any case at these assizes; that there was in the idea suggested as to the manner in which the wound was inflicted, something to prejudice the judgment which must be guarded against. He remarked, that the counsel for the prisoner had never adrerted to the deceased crying out, "Murder", and "Oh, Clarke, don't," three times ; he also made the observation I have already quoted as to the very great rarity of such cases.

The impression produced on my own mind when I listened to the charge was, that whatever effect the clever address of the counsel for the prisoner might have had on the jury, it had entirely failed with the judge in breaking down the medical evidence; and that, looking at the case through that evidence, he took a very grave $v i \in w$ of the nature of the offence-for offence he intimated that there must have been, if nothing more than a common assault. 
The jury found a verdict of Manslaughter. The judge, ater a day's consideration, sentenced the prisoner to the heaviest punishment he had it in his powrer to inflicttrensportation for life.

In passing sentence, the judge remarked that the prisoner had been found guilty of the manslaughter of his -ife under circumstances which, it had been proved, could not have resulted from accident; that he must be held responsible for an extraordinary wound, inflicted under the most extraordinary circumstances, and calling for the severest punishment. There could be little doubt, from his using such expressions, that the judge viewed the case as murder; and the question in his mind seemed to be, whether any of the accidents suggested by the defence, or the horrible idea of the puncture by the stick, best accounted for the death; and that he considered the latter did, and punished accordingly. That which I believe to have been the real explanation in no way seems to have been presented to the court.

I took a deep interest in this case; and, as my name at the time was associated with it, I think it right to say how far I was connected with it. My attention was first called to it, and my opinion asked, by a surgeon of this city, of the highest attainments and the soundest judgment; and, on reading the evidence given at the inquest, I found it closely accorded with his, that the view of the case taken by the medical witnesses-that the wound was a punctured one, and produced by some pointed instrument, such as a stick, thrust up-was by no means the only explanation which it would bear, and consequently was deeply unjust to the prisoner.

Shortly after this I was requested by the attorney for the prisoner to assist in the defence; and, with that view, an application was made by the attorney, on the prisoner's behalf, to the principal medical witness, to allow my inspection of the pudenda containing the wound, which had been removed at the post mortem examination, and which were in his possession. To this application a written refusal was made on the part of the three medical witnesses, instructed, as I understood, by the attorney for the prosecution. In this I thought then, as I think now, that they were wrong. I observe that, in the case of Regina $v$. Palmer, an application was lately made on the part of Palmer for permission to inspect a portion of the body, I think the ovarium, removed at the post mortem of one case, and the Attorney. General immediately acceded to the request. The arrangements at present acted on in criminal prosecutions give every facility for the production of evidence sgainst the accused, as far as expense goes; but if the accused be a poor man, it muy be literally impossible for him to bring a single witness in his favour. It is, I think, therefore, the more necessary that medical witnesses whose evidence is, after all, evidence of opinion, should jealously guard themselves against excluding the accused from access to what ought to be common to both parties, the ground on which such opinion is to be formed. The question is a very interesting and important one; but I will dismiss it with this remark, that I believe, from the readincss with which one of these gentlemen had previously given me a description of the wound, that if they had acted on their own good sense and good feeling, the refusal would nerer have been made. Immediately before the trial, I found that I had not succeeded in conveying to the prisoner's attorney anything like a clear impression of my view of the case, and consequently, speaking as a surgeon, of the defence which might and ought to be set up. I accordingly suggested the propriety of my meeting his counsel, but this he did not think necessary, and declined. It appeared to me that any further connexion with the case on my part would be wrong, as I might be held responsible for a defence which might prove, as it did prove, insufficient, without having had an opportunity of fairly stating that which in my judgment was the right one. I accordingly declined having anything more to do with the case, and went into court as a common spectator. Whilst there, I heard the principal counsel for the prisoner turn to his instructing attorney, and say, "I want s surgeon hero. You should have provided me with a eurgeon." The reply was, "I have one here"; and immediately I was requested to come and sit behind the counsel, which I declined doing, partly because I felt that the time was past when my advice could be of service; the line of defence had been doveloped in the cross-cxamination of the witnesses, and could not then have been well altered; partly, also, I felt. that the interview which had so shortly before taken place between me and the attorney did, as a matter of honour, entirely release me from all connexion or responsibility in the case. In truth, that happened which I feared wouldthat, however counsel may plume themselves on confusing medical witnesses, three men of education, judgment, and experience, are not to be broken down, except by some real difficulty thrown in their way; and that, generally speaking, counsel will require in such cases the assistance of a medical man to suggest what that difficulty is to be.

The point in which the defence appeared to me to fail was, that it did not account for the peculiar character of the wound. It was apparently a punctured wound. The attempt to explain this by an accidental wound from the stick could hardly fail to break down. One medical witness truly said, "The direction of the wound excludes the idea of its accidental production by the stick"; and another remarked, that if accidentally inflicted, it must have been by such a blow as a "dig with a stick". This, of course, was the idea suggested by the prosecution. The other at tempt to explain the punctured appearance of the wound was, that the angle of the pansherd produced it, by the elasticity of the parts allowing them to give way, and thus permitting it to enter more deeply than the extent of the mouth of the wound would explain. This explanation, though partly allowed by one witness, was directly denied by the others. The direction of the wound appears to me fatal to such an explanation. The mouth of the wound was above, nearest the arch of the pubes; the cul-de-sac below, towards the anus. The reverse ought to have been the case if effected by sitting down on a broken or breaking pan, as the force would be from below upwards, not from above downwards. This objection was taken by one witness, as I have stated, to the suggestion of the accidental wounding by the stick; but I do not remember that it was to that by the broken pan. I think it is also questionable whether an obtuse-angled pansherd would produce such a wound as described. It is much more likely to produce an open wound, as it did in the following case, lately mentioned to me. A lady, in making water, used the pot-dechambre, sitting on it; it broke beneath her, and serious hæmorrhage immediately occurred, which proceeded from a wound of the vulva; but this had not the appearance of a punctured, hut of an open incised wound.

I think, then, it is but fair to acknowledge, that if the explauation by the broken pan was not absolutely impossible, it was in a very high degree improbable, and certainly, except in the horrible guilt implied in such an explanation, much less probable than the explanation by a thrust with a stick, as suggested by the prosecution. That which I suggested at the time as the right line of defence was, that the wound was effected cither by her falling or being pushed down, whether backwards or forwards, and the body coming in contact with some obtuse body, even through her clothes, such as the angle of the seat of a chair, the stump of a bedstead, or even the pan, if she were bumped violently backwards on the floor, or, which I considered much the more probable explanation, that he had given her a kick on the rump;-that, whichever suggestion was taken, the explanation of the wound and of its peculiar character would be, that it was produced by the division of the soft structure of the vulva between the striking body, whether covered or not by her clothes, and the resisting bone beneath, particularly by its edge. And does not the character of the wound, as given in the medical evidence, amply bear out such an explanation? A wound of two and a half inches in length within the right labium minus, open for about an inch, followed 
the direction of the pubic ramus, outwards, downwards, and backwards, glancing over a portion of the bone of the pelvis-its direction being such that, if continued, it would have come out by the side of the anus behind.

Evidently, in the opinion of one medical witness, there was a relation between the wound and the subjacent bone; for be said that the bone underneath would give a direction to the wound, supposing it to be caused by a dig with - stick. It was evidently a lacerated wound: it is deseribed as appearing to have been produced by a bluntpointed instrument; that its production must have required much force, as grazing over the bone, partly soparating the head of the muscle; as having, in its whole length, the jagged appearance of torn muscle.

If, then, the different cases of injuries of the vulva which have been mentioned be considered in reference to the light they may throw on the question, How was the fatal wound in this last case inflicted ?-it will be seen that they lead to the following conclusions:-

That, as a general rule, wounds of the rulva are attended with severe, and sometimes, as in this case, with fatal hæmorrhage; that such hæmorrhage is explained by the anatomical structure of the parts, and its probability and degree increased by pregnancy.

That the relative position of the plane of the pubic arch allows such injuries of the vulva to be effected indifferently by a force from behind or in front; that the probability of its coming from behind would be increased by the woman being in a stooping position, and by her being large in the fanily way; and that, therefore, exceptis excipiendis, the wound in this case way have been produced by a kick in the rump.

That wounds of the vulva are frequently caused by the division of the soft parts by compression on the bone beneath, particularly its edge; that this circumstance explains the appearance which they assume of being punctured wounds, and will account for such appearance in the case under consideration.

Thus it would appear that there is a high probability in the supposition that this wound was inflicted by a kick or some such violence, accidental or intentional; whilst it is not to be denied that it may have been effected with the stick, as suggested. The direction of the wound downwards, in my opinion, would lessen the probability of its having been effected by the stick. It appears to me that it would most probably have been upwards, and at least directly inwards into the vagina. I do not, however, lay great stress on this supposition; but I think there can be no doubt that when, as surgeons, we account for death by a consideration of the nature of the injuries causing it, we are bound, of two explanations, even supposing them to be equally probable, to takc that most favourable to the accused. The prisoner's own account of the affair bore out this more favourable supposition. Before his trial I heard that he expressed his astonishment at the medical eridence; and after his conviction, when on his way to the scene of his punishment, he stated, on being interrogated on the subject, "It is no use for me now to conceal the truth; I know that my lot is fixed. I did not do what it was said I did, but I did what I know was very wrong. I came home, and found her drunk ; I got enraged, and I certainly did hick her." It will be remembered that his de. fence had been that the injury was accidental. I may also add, that a gentleman on the side of the prosecution has only lately remarked to me, in reference to this case, "No doubt in that case we were wrong".

I have been induced to bring this subject forward, not merely from the interest fairly attached to cases of such importance, but because $I$ believe it is a point in surgical jurisprudence hitherto not illustrated. A case will, I dare say, be remembered where a little girl was wounded in the vulva, and where the supposition was that it had been effected by an instrument pushed up through a grating. $M y$ recollection of the case is loose, and I do not know where to refer to it; but, from what I do remember of it, I think the explanation I have given of a blow against the bones of the pelris would equally explain it.

It has been my wish, in criticising the evidence of others, to do so fairly and dispassionately. The opinions which as surgeons we give in courts of justice, particularly where the issue is to be life or death, are fair suljects of criticism: nay, the public good demands that they be subjected to it.

\section{ON OSTEO-MYELITIS AFTER AMPUTATIONS.}

By Cuardes Kudn, M.l)., M.R.C.S.Eng., Fellow of the Surgical Suciety of Ireland, etc., London.

There is a purely medical or hygienic aspect under which the late surgical disasters in the Crimea may be re garded, that is entirely too much neglected just at present in England; yet the results of the late campaign are full of novelty, and very full of interesting instruction for hospital surgeons and practitioners generally through the country. Indeed, the old faniliar reports now made public from the pathological department of the English army by Dr. Lyons, as well as various returns made to the Emperor of the French by the pathologists at Pera and Marscilles, have opened up new and hitherto untrodden paths of research.

A purely medical disease of no small intercst, osteomyelitis, or inflammation of a bad character of the medulla of the long bones, has been much dwelt on recently by the French physicinus with the army in the Crimea, as common both in their hospitals and ours; so much so that disarticulations at the joints, so as not to expose the delicate tissue of the medulla and the internal liuing membrane of the medullary cavity, have been very generally substituted for amputations.

We have now the statistical results of the amputations and other cases in the late Crimean war:-10s per thousand died from surgical wounds in the Crimca; 391 per thousand from bad bygienic arrangements, scurry, and cold; while, at Scutari, 575 deaths in a thousand were from medical diseases with which the "civil element" was unable to cope, such as dysentery, pncumonia, osteo-myelitis, etc.; while 175 deaths in a thousand were from fever. The vast preponderance of medical diseases here must strike the most superficial reader.

The total of killed and wounded of our army in the Crimea up to September 1855 was 13,800 men in three nearly equal divisions; viz., from medical diseases in the trenches, assaults, and battles. The proportion of killed to wounded, curiously enough, is the same as at Waterloo-193 to 1,000 ; so that our surgery has not advanced on the field of battle.

We can compare these statistics in London better than any where else, as we have now a mass of reports from the French army of a most superior and valuable kind.

One cause of danger from amputations has been hitherto overlooked. A large number of the wounded at the battle of the Alma, and even a larger proportion of the wounded at the frightful affair of Inkermann, were obscrved afterwards to sink from a disease which, though well known to practical surgeons in hospitals of late years, has been yet not often described; viz., intiammation of the medullary canal and medulla (osteo-myelitis) of the long bones, due to meteorological influences in a great measure, also to too many amputations, and too much distrust of the unaided powers of Nature herself. This form of disease, observed in all the hospitals at Constantinople from the beginning of October to the end of December, was remarkable for coming on very like pyrmia, and for being, if possible, more dependent on meteorological influence than even that terribly fatal and unwelcome complication of wounds. In a word, the dangers of pyæmia and ostco-myelitis, from want of pure air in hospitals, especially in winter, to "burn off", in Liebig's phraseology, the pyogenic elements in the blood, the moment they make their first appearauce, has been too much overlooked. 